\title{
Leak detection in water distribution networks: an introductory overview
}

\author{
Samer El-Zahab ${ }^{1^{*}}$ (iD and Tarek Zayed $^{2}$
}

\author{
* Correspondence: samer.alzahab@ \\ hotmail.com \\ ${ }^{1}$ Department of Civil and \\ Environmental Engineering, Faculty \\ of Engineering, Phoenicia University, \\ Daoudiyeh, Lebanon \\ Full list of author information is \\ available at the end of the article
}

\begin{abstract}
Leaks in resource transmission pipelines is a growing concern for the water transmission industry. This creates a need to prevent the threat of leaks and minimize their damages through extensive research in leak detection technology. This research work provides a thorough investigation into the history of leak detection in pipelines by surveying the web of knowledge database and visualizing the outputs using visualization software VOSviewer and CiteNetExplorer. The analysis of the web of knowledge output presents a set of the ten most used keywords in the field of leak detection in pipelines that are further described and analyzed. Additionally, in-depth analysis of a randomly selected sample of papers was conducted to draw a sense of the progress in the industry over the past four decades. This article also defines a novel approach to define the leak detection phases, i.e., the identify-localize-pinpoint approach. Furthermore, two classes of leak detection systems are identified, static leak detection systems and dynamic leak detection systems. The two systems are defined as well as their differentiative capabilities. Finally, this article provides a summary of popular leak detection technologies to provide a broad sense of understanding for the leak detection field of research.
\end{abstract}

Keywords: Leak detection, Pipelines, Review paper, Leak detection technologies

\section{Introduction}

Water is a critical source of life on our planet; it plays paramount roles in agriculture, manufacturing, production of electricity, and to keep humanity healthy. Approximately one billion individuals around the globe are unable to access clean drinking water (Krchnak 2016). Urban water is regularly transmitted using underground pipelines. Water transmission pipelines periodically lose an average of $20 \%$ to $30 \%$ of the water transmitted through them, and those numbers can escalate above $50 \%$ in old systems especially ones that have suffered from inefficient maintenance. There are multiple causes for loss of water in transmission pipelines which include leakage, metering errors, public usage such as firefighting, and theft (Hunaidi 2000; El-Abbasy et al. 2016). The most critical route for losses is a leak, as they are considered to contribute an estimated of $70 \%$ of water loss in water transmission systems, this value is expected to become higher in undermanaged networks (Van Zyl and Clayton 2007). Comparatively, gas pipeline networks suffer from similar fates, yet the outcomes of leaks in gas pipelines can be more 
hazardous and more expensive than water leaks (Inaudi et al. 2008). In one instance, a study was conducted in the United Kingdom to identify the impact of those leaks on an urban water network. On a yearly basis, the country is expected to dig 4 million holes into its road network for pipe installations and leak repairs. The monetary impact of the repairs is estimated to be at 7 billion $£$ (around 10 billion US\$) annually. The overall cost can be divided into two main portions, 1.5 billion $£$ (around 2 billion US\$) indirect damage costs and 5.5 billion $£$ (around 8 billion US\$) in social impact costs (Royal et al. 2011). Another aspect of the dangers of leaks is their tendency to grow. The growth of leaks can allow the introduction of pathogens and contaminants from the surrounding environment into the network in the case of water networks and quite the opposite in the case of oil and gas networks which would result in dangerous impacts on human life (Alkasseh et al. 2013).

The losses and damages created by leaks required novel techniques and approaches to minimize their negative impact and deal with them as fast as possible. As a result, multiple researchers dedicated their efforts for the development of a vast variety of techniques for leak detection and leak location. This paper conducts an overview of the used leak detection techniques and the progress in the field of leak detection. To sum up the objectives of this review paper area:

(1) Conduct a thorough literature review on the topic of leak detection in pipelines.

(2) Present a study on the progress of leak detection approaches in recent years.

(3) Suggest approaches for evaluating leak detection techniques and technologies.

\section{Methodology}

The overall methodology of this literature survey can be summarized in Fig. 1. The first step of this research is to gather a substantial amount of the published works on leak detection in urban water mains. For this purpose, the Web of Knowledge (WoK) database was selected as the main database to conduct the search. The main keywords of the search are "leak detection in pipelines". The data collected from the WoK database will be analyzed to have a sense of the historical, technological, and demographical trends in pipeline leak detection research. The second step is to randomly select between 30 to 35 papers on the topic and analyze the chosen papers with more depth. This is based on the assumption that $n=30$ is a boundary between small and large samples (Hogg and Tanis 2006). This approach creates two main datasets, the WoK dataset which contains nearly 1000 papers on the topic of leak detection pipelines and the in-depth dataset for this research article that studies a randomly selected collection of papers. The in-depth dataset will be analyzed to inspect the capabilities and technologies used. Additionally, the papers will be assessed for their historical progression and the distribution of the models on the level of technologies used and the capabilities the models provide. This analysis allows the development of a general sense of the progression and flow of leak detection research.

\section{Defining leak detection}

In 2009, Hamilton defined leak detection as a subsidiary of three main phases know as localize, locate, and pinpoint or LLP. In Table 1, localize is defined as narrowing down 


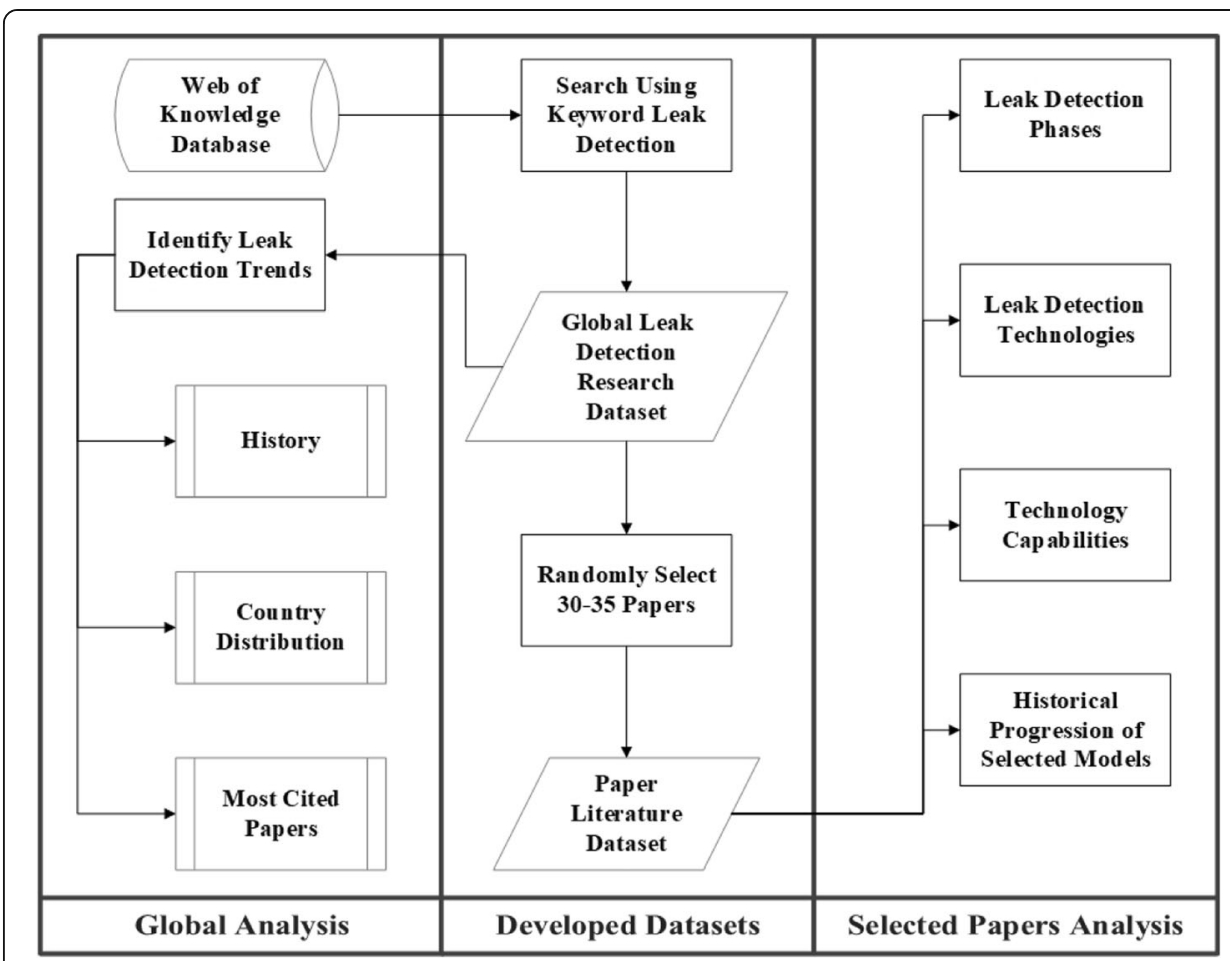

Fig. 1 Paper Methodology. The figure displays three main categories with their respective steps that were utilized in research. The arrow means feeds into or factors into

a leak to a specific segment within the network or a specific district metered area after the suspicion of a leak. Several tools can be used in this domain such as district metered area and fitting surveys (El-Abbasy et al. 2016; Li et al. 2011). The second phase is locating, and it is the first phase where a location for the leak is determined. According to Hamilton, the location of the leak is said to be within a radius $0030 \mathrm{~cm}$. Furthermore, multiple tools are available for utility in this phase including correlators and microelectromechanical sensors (Hamilton 2009; El-abbasy et al. 2014; El-Zahab et al. 2016; Martini et al. 2015). Finally, the third phase, according to Hamilton, would be pinpointing. Pinpointing is another phase where another estimate for the exact location of the leak is determined but within a radius of $20 \mathrm{~cm}$. In this phase, a variety of tools are available including hydrophones and geophones (Fantozzi et al. 2009; Royal et al. 2011). The difference provided by Hamilton between locating and pinpointing is a 10 $\mathrm{cm}$-difference in radius, which is negligible and offers no actual differentiation between the processes or the actual outcome of each phase. Therefore, it is more efficient to merge the two phases due to similarity. In contrast, multiple researchers in the field of leak detection have highlighted the existence of another challenging aspect in the

Table 1 Phases of Leak Detection - ILLP

\begin{tabular}{ll}
\hline Phase & Definition \\
\hline Identify & Determine the existence of a leak and distinguish leaks from false alarms. \\
Localize & Narrow down the location of a leak to a specific area or segment. \\
Locate & Determine the location of a leak with a radius of $30 \mathrm{~cm}$. \\
Pinpoint & Determine the location of a leak with a radius of $20 \mathrm{~cm}$. \\
\hline
\end{tabular}


development of leak detection systems and approaches. The challenge lies in differentiating the signs of leaks from other aspects such as pumps or an open hydrant. This problem is vivid in acoustic noise loggers and accelerometers and other wireless sensor devices that are used in leak detection. Sensors would pick up any form of signs and signals similar to those of leaks and end up providing false alarms. False alarms create an expenditure of workforce and funds for the bodies monitoring the respective networks (El-Zahab et al. 2016; Khulief et al. 2012; Stoianov et al. 2007a, 2007b). Therefore, a new phase of leak detection is proposed, and that is the identification phase. As described in Table 1 , the identification phase works towards determining if the signs detect and the signals derived indicate a leak in the network of pipelines or not and how to differentiate between leaks and other factors affecting the network. Subsequently, the leak detection phases can now be summed up as ILLP, identify-localizelocate-pinpoint. It is highly possible to merge locating and pinpointing due to the 10$\mathrm{cm}$ difference between the two phases. This approach helps in creating three distinct and unambiguous phases. Thus, another approach would be the ILP approach, identification-localization-pinpointing. Where the first step identifies the existence of a leak, the second phase identifies the segment where the leak is, and finally, the third phase would determine the exact location of the leak with a certain accuracy.

\section{Progress in leak detection research}

The advances in leak detection research have grown remarkably in recent years, but the field of leak detection is not a new field of research. The damages created by leaks in pipeline networks presented researches with the curiosity of developing reliable and immediate solutions to fight the leakage epidemic. In a survey performed on the Web of Knowledge database, 941 scholarly articles about the topic of leak detection in pipelines were found. A timeline analysis was conducted for the most referenced papers in the field of leak detection using the CitNetExplorer software for bibliometric analysis (Van Eck and Waltman 2014). The results of this analysis are illustrated in Fig. 2, The first paper found by this survey existed in the year 1968 by Zielke as displayed in Fig. 2, who suggested the study of wall shear stress in laminar pipe flow along with the mean velocity of the flow and the changes in the velocity can aid in detecting any anomalies within the pipeline. The figure further displays that the research in the field of leak detection started booming further in the mid-1980s. Beyond that point, the research field started gaining more and more attention especially after 1994. After the year 2000, research in leak detection saw numerous publications and contributions with the rise of the importance of water conservation and water scarcity and the abundance of novel technologies that are capable of facilitating and automating the leak detection process.

The dataset was further studied using another bibliometric analysis software that is named VOSviewer (Van Eck and Waltman 2010). Figure 3 was established using the software. The figure aims to establish the countries with the most interest in researching the field of pipeline leak detection and to provide a sense of the number of publications provided by those countries. In the figure, the countries with at least 25 publications in the field of pipeline leak detection are displayed. Starting with Germany with 25 publications in the field within the Web of Knowledge database and moving all the way up to Canada with 58 publications in the field, then England with 74 publications in the field, exceeded by the United States of America with a sum of 144 


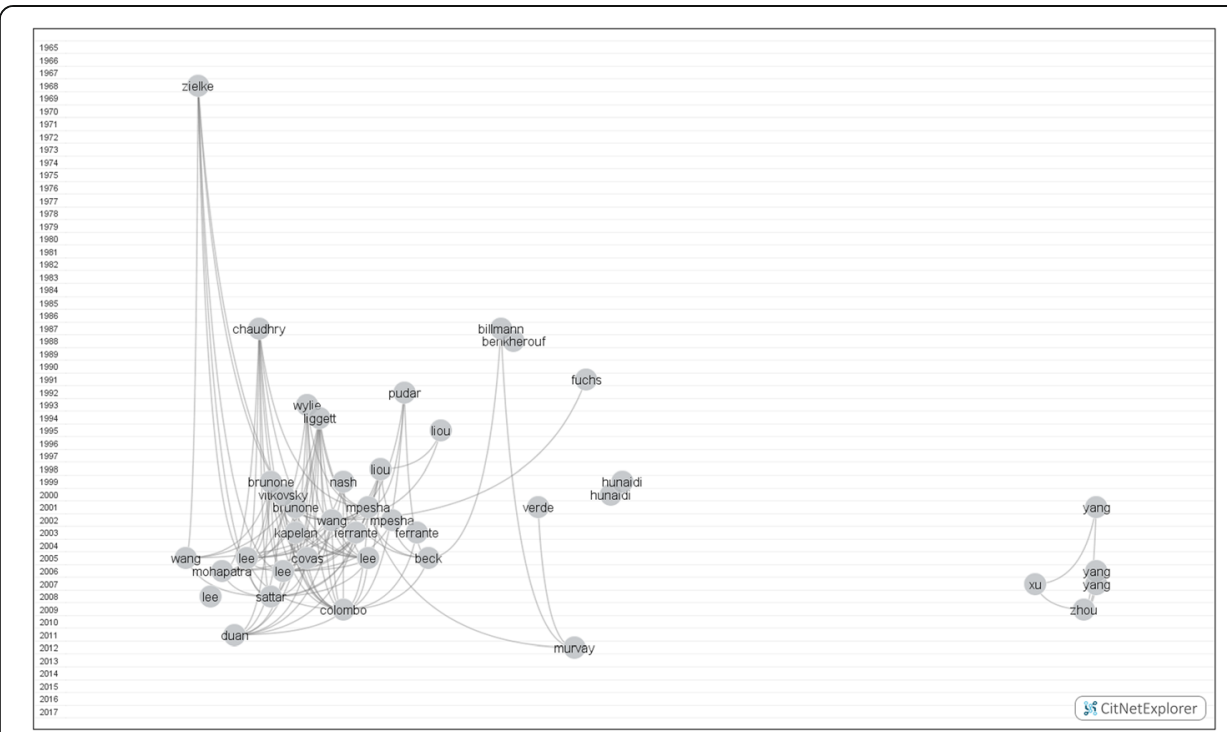

Fig. 2 Chronological display of the most cited papers to date. The $y$-axis represents the years in which the represented papers in circles where published. The circles represent the most cited papers in the field of leak detection. The connections represent the forward citations between those paper i.e. the foremost paper has cited the publication at the origin of the connection

publications, and finally on top of the list is the People's Republic of China with 263 publications. The proximity between the globes highlights the amount of co-authored works as well. Therefore, from the figure, it is deductible that the People's Republic of China had multiple co-authored works with England. Same goes for Australia and South Korea as well as the United States of America, Germany, and Saudi Arabia.

After studying the geographical distribution of research interests, the next step is to analyze the most repetitive keywords in the global dataset provided by WoK. Figure 4 displays the top ten most used words within the collected dataset. The figure starts at number 1 and ends at number 10. The first keyword with the most prominent

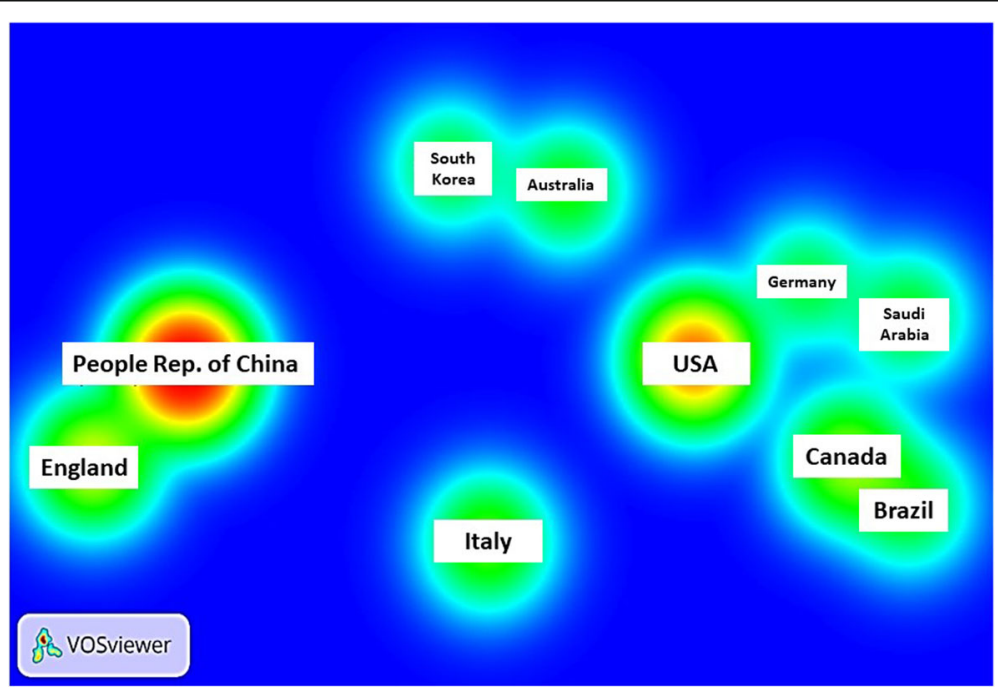

Fig. 3 Bubble graph showing the most publishing countries in the leak detection field. Each bubble represents a country. The more publications a country has the bigger the bubble is. As bubbles grow larger, colors such as yellow, orange and red are added for clarification 


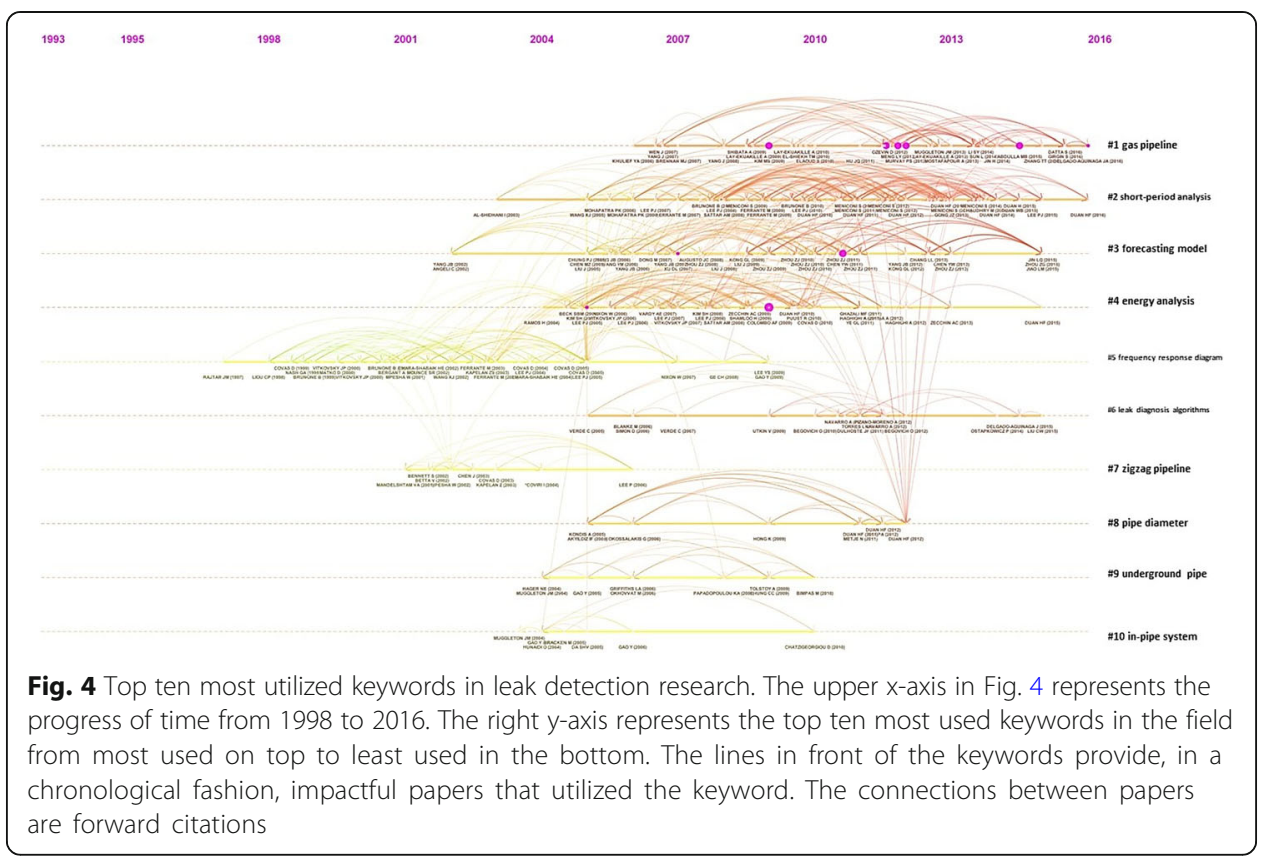

recurrence is "gas pipelines". The importance of gas pipelines is relative to the criticalness of the material they transport. Natural gas and oil are hazardous materials that are transported in a pressurized state. Therefore, any leakage will have a tremendous impact in a small time. The impacts of leaks in gas pipelines include major economic losses along with the pollution of the surrounding environment and a grand possibility for injuring personnel (Geiger et al. 2006; Inaudi et al. 2008; Sun et al. 2011). The second most common keyword is "short period analysis". The keyword refers to the analysis that focuses on the first characteristic time of the pipe. The analysis revolves mainly around pressure transients within pipelines due to leaks and conducts analysis based on the time and frequency domains and it considers the conditions at minor losses as boundaries for the analysis (Meniconi et al. 2010). The third keyword is "forecasting model" which are also known as prediction models. Prediction models play key roles in leak detection as they utilize learned historical data to make a calculated decision for future leaks. Additionally, forecasting models can learn and progress through time as they incur new information. Forecasting models are usually used with leak detection technologies to develop thresholds and equations that are capable of detecting and locating leaks (El-Abbasy et al. 2016; El-Zahab et al. 2016; Fahmy and Moselhi 2009; Whittle et al. 2010). The fourth most recurring keyword in the dataset is "energy analysis". The term energy analysis refers to the study of the anomalies created by the reflected energy caused by leaks in pipelines. The term may also refer to the study of the variation of energy consumption by pumps surrounding leaks to maintain a stable pressure. In both cases, the persistence of a disruption indicates the existence of leakage and accordingly, it can be localized (Belouchrani et al. 2013; Mostafapour and Davoudi 2013; Shibley 2013). The fifth most recurring keyword is "frequency response diagram". The figure shows that the frequency response analysis is the oldest recurring keyword within the data set under study. Frequency response is one of the oldest techniques in leak detection. It relies on studying the response to an excitation frequency 
within a pipeline. The method studies the frequency diagram provided as a result of the excitation and accordingly detects leaks (Brennan et al. 2007; Mpesha et al. 2001). The keyword with the sixth place in recurrences is "leak diagnosis algorithm". Leak diagnosis algorithms are mathematical or artificial intelligence and machine learning models that utilize available data to automatically identify, locate, or pinpoint leaks. Those algorithms can be paired with a wide variety of technologies such as infrared, ground penetrating radar, and noise loggers. Some of the algorithms that are used include support vector machines, artificial neural networks, and genetic algorithms (ElAbbasy et al. 2016; El-Zahab et al. 2017; Fahmy and Moselhi 2009; Al Hawari et al. 2015, 2016). In the seventh place comes the keyword "zigzag pipeline" which refers to pipelines that are not linear and have some turns and unique shapes within their structure. Those pipelines include pipelines that are part of an L-shape or T-shape structure. The importance of those pipelines lies in the fact that the unique changes in their shapes create new challenges and parameters for leak detection by altering the collected data. Therefore, extra care and attention are invested in this abundant class of pipelines (Datta and Sarkar 2016; Lay-Ekuakille et al. 2009, 2010). In the eighth position of the list comes the keyword "pipe diameter". The diameters of pipelines that are studied for leaks have proven to be a critical factor in the leak detection process for multiple technologies and techniques. The smaller a pipeline is, the more likely it is for the leak signal to travel longer distances based on the leak size. Therefore, the diameter of pipelines is an important parameter in multiple research works (Covas et al. 2005; Hauge et al. 2007). In the ninth standing is the keyword "underground pipe". Underground pipelines are a crucial element in the leak detection study as urban infrastructure systems are mostly deployed underground. That is why a substantial amount of research is conducted on underground pipes and also simulative experiments where pipes are tested in underground-like conditions (Mashford et al. 2009; Rajani and Kleiner 2001; Stoianov et al. 2007a, 2007b). Finally, in the tenth position is the keyword "in-pipe system", which a form of a static leak detection system. In-pipe systems rely on the placement of sensors within networks. Those sensors are connected to a main data collection server by means of communication technology such as 3G. The data is then received in a timely fashion at the headquarters of the operator. Accordingly, analysis can be conducted in a timely fashion as well or using software. In-pipe systems allow for the immediate detection of leaks and that is why they are a growing leak detection topic recently (El-Abbasy et al. 2016; El-Zahab et al. 2017; Srirangarajan et al. 2013; Stoianov et al. 2007a, 2007b).

\section{Classes of leak detection models}

Through the observation of the literature and the applied works in leak detection, two main categories of leak detection systems can be identified. The categories are static (or stationary) leak detection and dynamic (or mobile) leak detection. Although each class on its own is capable of identifying, locating, and pinpointing leaks, it is not uncommon to utilize a combination of both classes (Atef et al. 2016; Billmann and Isermann 1987; Romano et al. 2017). The two classes of leak detection system can be defined as follows: 
- Static leak detection systems: are systems that rely on sensors and data collectors that are placed within the water network and on valves and are capable of transmitting periodical data to the network management office. This data can be used to identify, localize, and pinpoint leaks.

- Dynamic leak detection systems: are systems that rely on moving leak detection devices to suspected leakage area to perform an investigation. Therefore, they rely initially on suspicion of an existing leak. Another approach is performing regular surveys around cities to identify leaks as soon as possible. Those systems can confirm the existence of leaks and immediately localize and pinpoint them.

The main distinction between the two classes is that static leak detection systems can inform the water network management of the existence of a leak almost immediately, whereas dynamic leak detection systems are required to have information of a leak possibility so that they can be mobilized for investigation. On the other hand, dynamic leak detection systems can pinpoint the exact location of a leak almost immediately under ideal operating conditions, whereas static leak detection systems will provide a location within a certain area and they are also more prone to false alarms. It is not uncommon to use a static leak detection system to detect leaks and a dynamic leak detection system to pinpoint them, but that is not expected to be the most affordable route (Cataldo et al. 2014; Lee et al. 2005). The two classes encompass a wide variety of technologies to provide an accurate leak detection system, but the technologies are not limited to one class. For example, acoustic technologies, specifically noise loggers, can be dynamic and moved from one location to the other periodically to detect leaks as in (Hunaidi and Wang 2006) or they can be left in the network as in (El-Zahab et al. 2017).

\section{Analysis of selected papers}

This analysis aims to get a sense of the research work published in leak detection in pipelines. Therefore, the first goal was to collect between 30 to 35 papers at random and analyze the models described in those papers in depth. At first 50 papers were selected from the original 941 papers and then those papers are filtered for redundancy and similarity to keep only distinct papers. If after the filtering the number of journals is between 30 and 35, no further search is needed. Otherwise, ten new random papers would be selected. Table 2 shows that from the original 50 papers selected only 31 remained after filtering and therefore no further search was conducted. Table 2 summarizes the titles, year of publications, and respective reference of each paper.

The first step of the analysis is to study the distribution of the randomly selected journals over the years. This study provides insight into the condition of the research field over the years. Figure 5 shows that research into the field of leak detection in pipelines commenced in the 1980s but had little attention due to it being a new concept. The interest started growing over the years as double the amount of the randomly selected papers in the following decade. With the beginning of the twenty-first century, the field of leak detection in pipelines started gathering more attention and funding creating a burst of research that continues until today.

Through the study of the literature, two classes of leak detection systems were identified. The classes are (1) static leak detection and (2) dynamic leak detection. Static leak detection represents a leak detection system that is left in the network and does not 
Table $\mathbf{2}$ List of randomly selected publications

\begin{tabular}{|c|c|c|c|}
\hline No & Title & Year & Reference \\
\hline 1 & $\begin{array}{l}\text { Identifying Water Main Leaks With Trihalomethane } \\
\text { Tracers }\end{array}$ & 1985 & (Hargesheimer et al. 1985) \\
\hline 2 & Leak Detection Methods for Pipelines & 1987 & (Billmann and Isermann 1987) \\
\hline 3 & $\begin{array}{l}\text { Ten Years of Experience with Leak Detection by } \\
\text { Acoustic Signal Analysis }\end{array}$ & 1991 & (Fuchs and Riehle 1991) \\
\hline 4 & $\begin{array}{l}\text { Designing a Cost Effective and Reliable Pipeline Leak } \\
\text { Detection System }\end{array}$ & 1997 & (Zhang 1997) \\
\hline 5 & $\begin{array}{l}\text { Ground-penetrating radar for detection of leaks in } \\
\text { buried plastic water distribution pipes }\end{array}$ & 1998 & (Hunaidi and Giamou 1998) \\
\hline 6 & $\begin{array}{l}\text { Acoustical characteristics of leak signals in plastic water } \\
\text { distribution pipes }\end{array}$ & 1999 & (Hunaidi and Chu 1999) \\
\hline 7 & $\begin{array}{l}\text { Leak Detection And Calibration Using Transients And } \\
\text { Genetic Algorithms }\end{array}$ & 2000 & (Vítkovský et al. 2000) \\
\hline 8 & Detecting Leak in Plastic Pipes & 2000 & (Hunaidi et al. 2000) \\
\hline 9 & $\begin{array}{l}\text { Acoustic methods for locating leaks in municipal water } \\
\text { pipe networks }\end{array}$ & 2004 & (Hunaidi et al. 2004) \\
\hline 10 & Frequency domain analysis for detecting pipeline leaks & 2005 & (Lee et al. 2005) \\
\hline 11 & $\begin{array}{l}\text { Pipeline Network Features and Leak Detection by Cross- } \\
\text { Correlation Analysis of Reflected Waves }\end{array}$ & 2005 & (Beck et al. 2005) \\
\hline 12 & $\begin{array}{l}\text { A New system for locating leaks in urban water distribution } \\
\text { pipes }\end{array}$ & 2006 & (Hunaidi and Wang 2006) \\
\hline 13 & PIPENET: A Wireless Sensor Network for Pipeline Monitoring & 2007 & (Stoianov et al. 2007a, 2007b) \\
\hline 14 & Comparison of two Detection Algorithms for Pipeline Leaks & 2007 & (Begovich et al. 2007) \\
\hline 15 & $\begin{array}{l}\text { Fiber optic in-line distributed sensor for detection and } \\
\text { localization of the pipeline leaks }\end{array}$ & 2007 & (Huang et al. 2007) \\
\hline 16 & $\begin{array}{l}\text { Water loss detection via genetic algorithm optimization-based } \\
\text { model calibration }\end{array}$ & 2008 & (Wu and Sage 2008) \\
\hline 17 & $\begin{array}{l}\text { Detecting and locating leaks in underground water mains } \\
\text { using thermography }\end{array}$ & 2009 & (Fahmy and Moselhi 2009) \\
\hline 18 & $\begin{array}{l}\text { A selective literature review of transient-based leak detection } \\
\text { methods }\end{array}$ & 2009 & (Colombo et al. 2009) \\
\hline 19 & $\begin{array}{l}\text { Pressure-dependent leak detection model and its application } \\
\text { to a district water system }\end{array}$ & 2009 & (Wu et al. 2009) \\
\hline 20 & $\begin{array}{l}\text { Leak detection and isolation in water distribution networks } \\
\text { using principal component analysis and structured residuals }\end{array}$ & 2010 & (Gertler et al. 2010) \\
\hline 21 & $\begin{array}{l}\text { Detecting and Locating Leaks in Water Distribution } \\
\text { Polyethylene Pipes }\end{array}$ & 2010 & (Pal et al. 2010) \\
\hline 22 & $\begin{array}{l}\text { Acoustic Detection of Leaks in Water Pipelines Using } \\
\text { Measurements inside Pipe }\end{array}$ & 2011 & (Khulief et al. 2011) \\
\hline 23 & $\begin{array}{l}\text { Time domain reflectometry, ground penetrating radar and } \\
\text { electrical resistivity tomography: a comparative analysis of } \\
\text { alternative approaches for leak detection in underground pipes }\end{array}$ & 2014 & (Cataldo et al. 2014) \\
\hline 24 & $\begin{array}{l}\text { SmartPipes: Smart Wireless Sensor Networks for Leak Detection } \\
\text { in Water Pipelines }\end{array}$ & 2014 & (Sadeghioon et al. 2014) \\
\hline 25 & $\begin{array}{l}\text { Multi-tier method using infrared photography and GPR to } \\
\text { detect and locate water leaks }\end{array}$ & 2016 & (Atef et al. 2016) \\
\hline 26 & $\begin{array}{l}\text { Mobile sensor networks for optimal leak and backflow detection } \\
\text { and localization in municipal water networks }\end{array}$ & 2016 & (Gong et al. 2016) \\
\hline 27 & Wireless Gas Leak Detection and Localization & 2016 & (Chraim et al. 2016) \\
\hline 28 & Leak Detection, Size Estimation and Localization in Pipe Flows & 2016 & (Aamo 2016) \\
\hline 29 & $\begin{array}{l}\text { Perturbation mapping of water leak in buried water pipes via } \\
\text { laboratory validation experiments with high-frequency ground } \\
\text { penetrating radar (GPR) }\end{array}$ & 2016 & (Lai et al. 2016) \\
\hline 30 & Locating leaks in water mains using noise loggers & 2016 & (El-Abbasy et al. 2016) \\
\hline 31 & $\begin{array}{l}\text { Statistical process control-based system for approximate location } \\
\text { pipe bursts and leaks in water distribution systems }\end{array}$ & 2017 & (Romano et al. 2017) \\
\hline
\end{tabular}




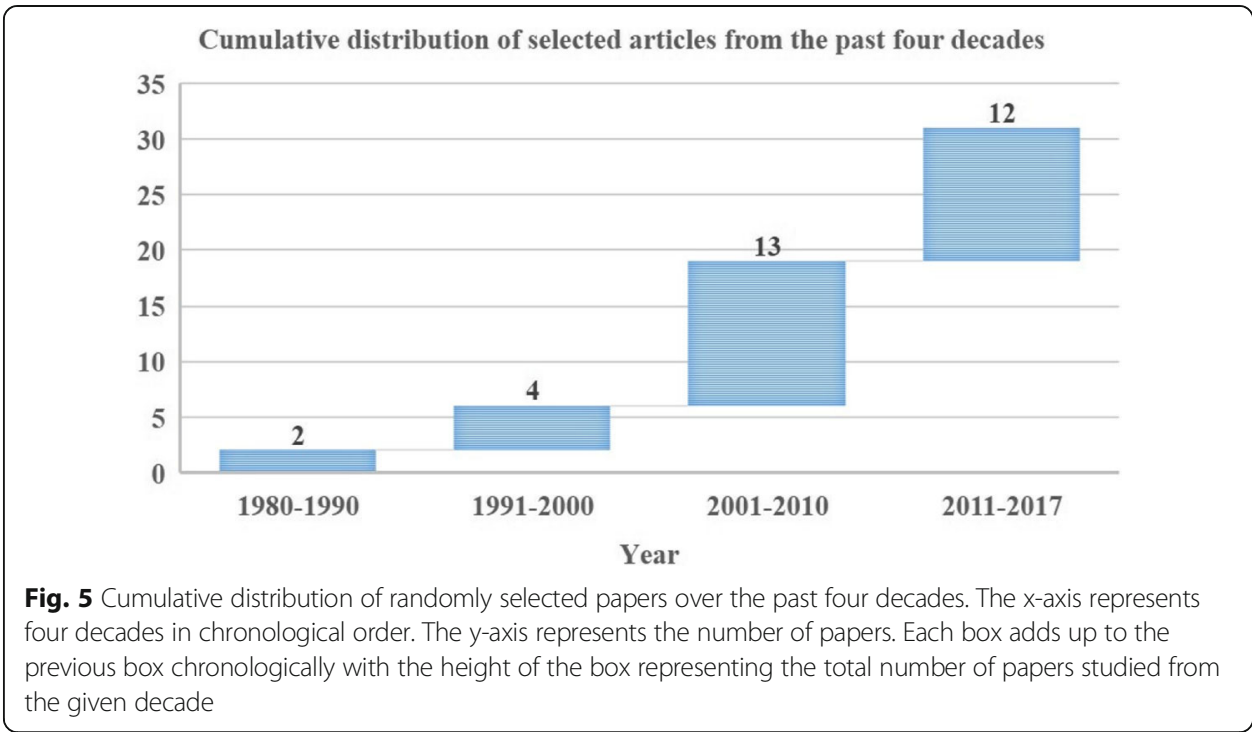

require the arrival of an inspection crew to detect leaks. Static leak detection systems rely on sensors of any leak detection capable technology coupled with a communication technology such as broadband or GSM. On the other hand, dynamic leak detection systems require the mobilization of a leak inspection team that delivers the devices to the suspected leak site to perform an inspection and confirm or clear the suspicion. Some examples of such systems include moving infrared cars, moving ground penetrating radar cars, and hydrophone systems. Figure 6 presents a study of capabilities amidst the randomly selected models. The two papers found in the 1980s encompassed three models. Two dynamic models were investigated, and one static model was proposed using devices that are currently referred to as noise loggers. With the advancement of device communication technology, the field of static leak detection has received growing attention starting in the 1990s where new devices and models were proposed. The main difference between the two classes is that static leak detection systems are capable of identifying the existence of leak as soon as a leak occurs, whereas dynamic leak

\section{PERCENT DISTRIBUTION OF MODEL CLASSES AMIDST SELECTED MODELS}

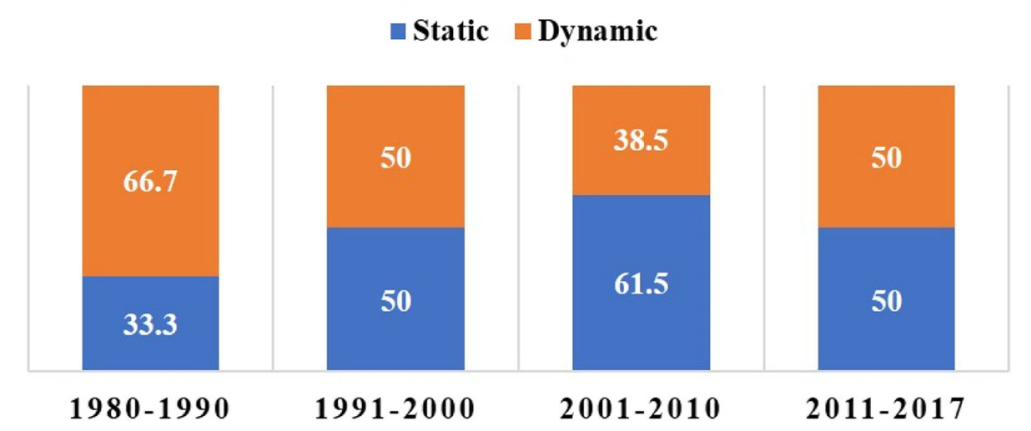

Fig. 6 Distribution of static and dynamic models over the past four decades. The $x$-axis represents the decades under study. Each bar represents the papers for that specific decade and has a value of 100\%. Dynamic models are represented in orange and static models are in blue. The values inside the boxes represent the percentage that each class contributes to the overall amount of papers 
detection systems require suspicion and transport. On the other hand, once dynamic leak detection systems arrive at the suspected leak site, they can confirm the existence of the leak and identify its exact leak location with high accuracy. The random data gathered during the decade between 2001 and 2010, shows that research interest is becoming prevalent in static leak detection as it provides municipalities with the comfort of detecting leaks with minimum manpower. The field is increasing in demand today with a sizable amount of companies providing different technologies and services for static leak detection. Regardless, due to the inaccuracies due to false alarms and noise interference in static leak detection, municipalities still rely on dynamic leak detection to give the final answer in cases of doubt. Accordingly, both static and dynamic leak detection receive a similar amount of research interest today.

In Fig. 7, the models were assessed for their capabilities throughout the years. Initially, an early static identification model was suggested but not implemented. The applied models favored application to localize or pinpoint leaks. With more experience in leak detection, new challenges arise regarding leak identification, specifically, identifying leak data from other sorts of data such as pump data in acoustic studies. The challenge of differentiating between leaks and other sources grows as the percentage of identification models between 2001 and 2010 reaches $56.3 \%$ of the selected models for the decade. In the current decade, localization and identification of leaks are still major topics with each having $38.5 \%$ of the selected papers from the current decade. This shows that with the rise of static leak detection, the need to eliminate noise and other non-leak sources became a critical aspect of leak detection. Additionally, the shift towards static leak pinpointing provides a big room for contribution in the field.

Another aspect of the study is to identify the uses of static and dynamic models. Figure 8 shows that static models are mostly used for the identification of leaks with $50 \%$ of the developed research models are for either identifying leak existence or differentiating leak sources from other sources. The remaining $50 \%$ for static leak detection systems is distributed equally between localizing a leak area and pinpointing the exact

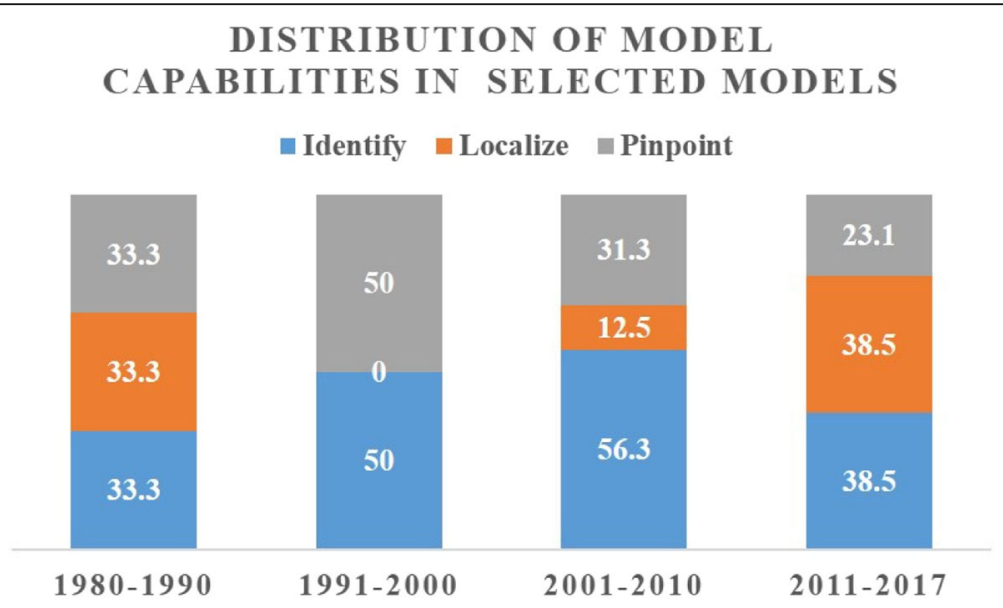

Fig. 7 Capabilities of the randomly selected models from the past four decades. The $x$-axis represents the decades under study. Each bar represents the papers for that specific decade and has a value of $100 \%$. The three capabilities of leak detection models are identified via distinctive colors. Identify is in blue, localize is in orange, and pinpoint is in grey. The values inside the boxes represent the percentage that each capability contributes to the overall amount of papers for a given decade 


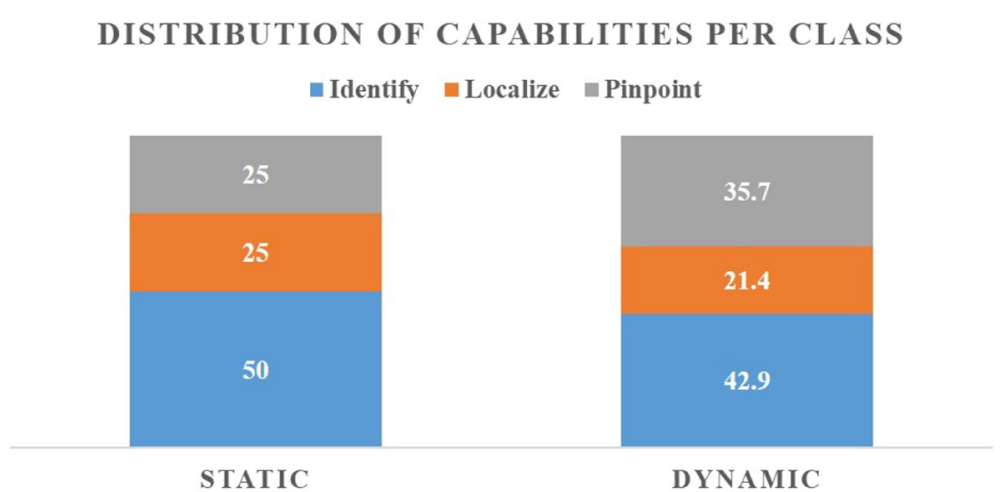

Fig. 8 Distribution of capabilities per class of models. The $x$-axis represents the classes of models, static or dynamic. Each bar represents the population of papers in that class. The three capabilities of leak detection models are identified via distinctive colors. Identify is in blue, localize is in orange, and pinpoint is in grey. The values inside the boxes represent the percentage that each capability contributes to the overall number of models per class

location of a leak. On the other hand, dynamic leak detection systems are mostly used to identify and pinpoint leaks. That is mainly due to their capabilities of identifying anomalies on the spot when applied. Dynamic leak detection systems can also be used for leak identification through regular surveying of leak susceptible areas. Even then, dynamic leak detection systems can pinpoint the leak location after identifying it.

With the progression of the years, more technologies were utilized in various areas of leak detection. Figure 9 shows that the initial technologies found in the sample under study were acoustic technologies and tracer gases. Both technologies are relatively simple to use and implement. New technologies were introduced in the following decade including vibration measurements, pressure measurement sensors, and ground penetrating radar. Those technologies may have been used earlier, especially pressure, but

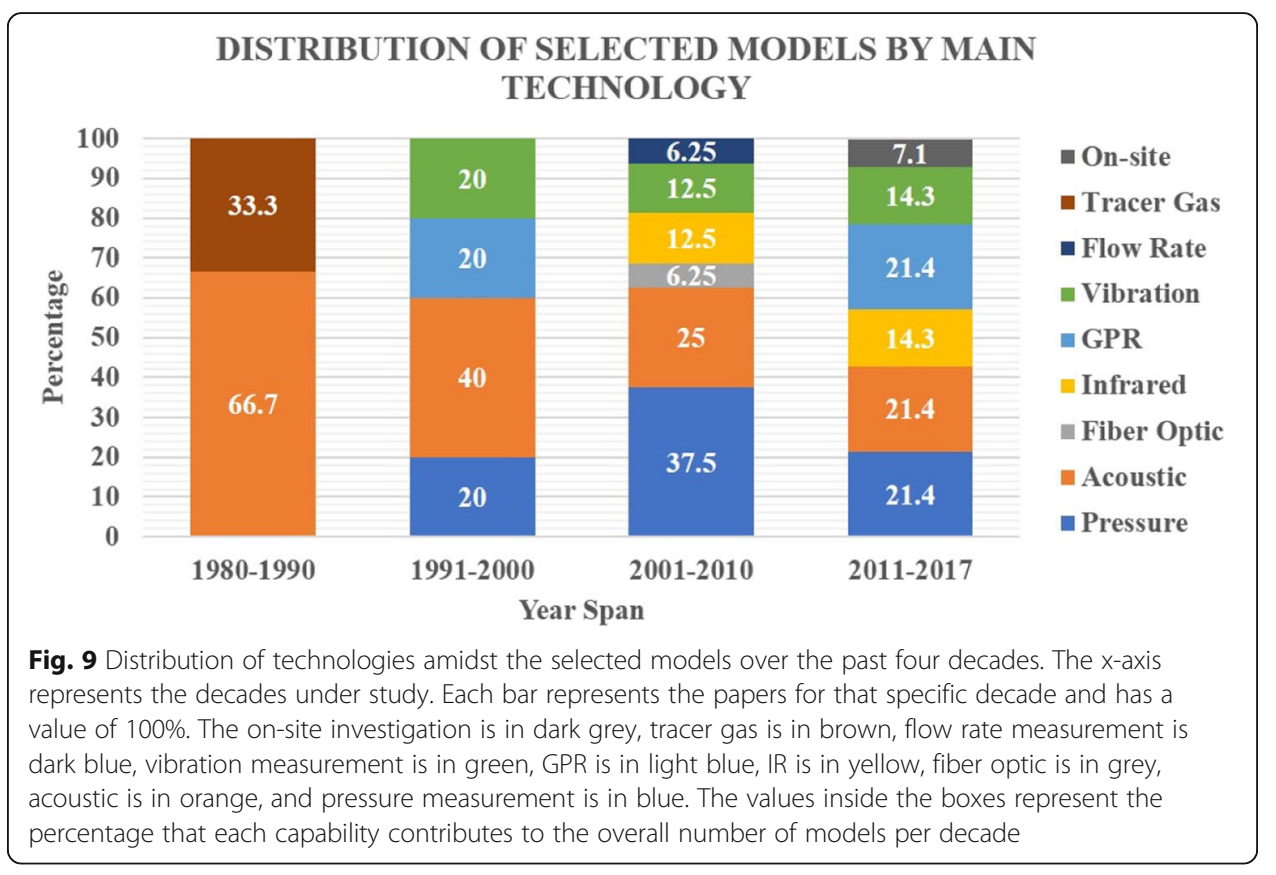


the set of papers at hand does not provide models using pressure measurement technologies until the 1990s. In the 2000s a greater variety of technologies is present with the addition of fiber optic sensors, infrared photogrammetry, and flow rate analysis. This attests to the growth in leak detection research and the wide set of technologies and contributions available. This shows that acoustic and pressure-based leak detection approaches are the most established leak detection methods available today, but they both still have sufficient rooms for contribution in research yet not as much as the novel technologies that are on the rise.

An abundance of leak detection technologies is noticed within the selected sample of papers. This variety is further illustrated in Fig. 10. The figure shows that more than $50 \%$ of the models relied on either acoustic based hardware or pressure-based hardware with $29 \%$ and $26.4 \%$ respectively. This level of use can be explained by the promising results provided by each technology over the years in addition to them being two of the oldest technologies in the field as well. Additionally, new and promising technologies are available in the sample including GPR and infrared which have received a substantial amount of attention that is directed towards maximizing their operational limits along with vibration sensors which are providing promising results on multiple aspects of leak detection.

\section{Leak detection technologies overview}

Multiple technologies have been developed throughout the years to help identify and locate leaks within water networks. In this review, the modern state-of-the-art techniques will be reviewed, and their advantages and disadvantages will be pointed out.

\section{Listening devices}

Both electrical and mechanical geophones are used to listen to buried water pipelines from the surface. These devices are accurate and highly sensitive that they can detect the exact location of the leak, and also cheap to purchase and easy to set up. The

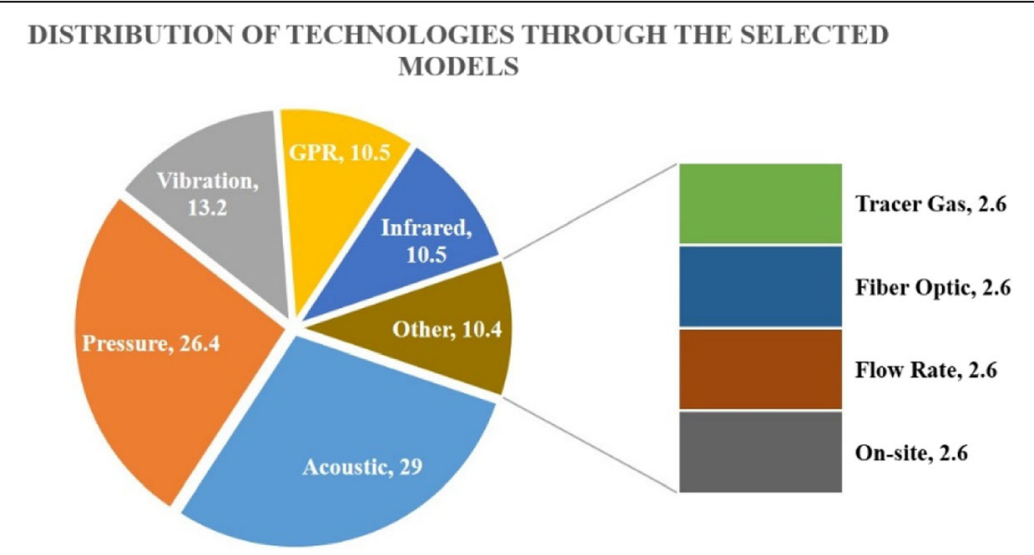

Fig. 10 Distribution of technologies amidst the selected models. The pie chart represents the distribution of technologies amidst all the studied models. The on-site investigation is in dark grey, tracer gas is in green, flow rate measurement is in brown, vibration measurement is in grey, GPR is in yellow, IR is in blue, fiber optic is in dark blue, acoustic is in light blue, and pressure measurement is in orange. The values inside the boxes represent the percentage that each capability contributes to the overall number of models 
accuracy of geophones depends highly on the proficiency and the experience of the operator, and it also might fail to detect some leak classes. Furthermore, the exact location of the pipeline to be assessed must be marked so that the operator would know where to put the device. The examination renders the area above the pipe unusable in case it is a street or highly utilized area. Similar to Geophones, Hydrophones try to listen to leaks by sometimes being placed in the system and rarely on the surface of the ground. Hydrophones can be more accurate than geophones in detecting leaks but they require more training than geophones to operate, and they are approximately seven times more expensive than geophones (United States Environmental Protection Agency 2009). To detect a leak, these devices rely on the high-frequency acoustic signals sent by the release of pressurized fluids, to detect leak existence and leak locations. Sound frequencies are then amplified and filtered at $1 \mathrm{kHz}$ using a preamplifier to remove highfrequency noises that are not related to the network. By measuring the time delay between two detection instants between two given listeners the leak can be pinpointed by relating propagation speed within the medium with time and distance.

Another listening approach would be the use of listening sticks which are extended earpieces. This approach is highly dependent on the ability of the operator to listen and distinguish leak sounds properly. This approach is most suited for metallic pipelines between $75 \mathrm{~mm}$ and $250 \mathrm{~mm}$ in diameter and having preferably a pressure equal to or higher than $10 \mathrm{~m}$ or $15 \mathrm{psi}$. The accuracy of listening rods is independent of material type and thus it can be used in a versatile manner yet the overall hearing experience is deterred by the existence of external noise (Hamilton and Charalambous 2013).

The aforementioned technologies are versatile and provide fast on-site leak detection in suspected areas for any type of transmission pipelines. On the other hand, they rely heavily on human senses and interpretation and are susceptible to inaccuracies due to external mechanical noise. Therefore, such models can be improved further by reducing the impact of noise using advanced signal analysis and filtering in addition to processing automation which eliminates the dependency on human listening and replaces it with computer analysis (Hamilton and Charalambous 2013).

\section{Leak noise loggers}

Leak Noise loggers are placed in utility holes without any trenching or drilling; they can be used as a permanent monitoring, semi-permanent monitoring, or leak surveying technique. They can be placed in networks as displayed in Fig. 11. Noise Loggers operate by implementing sophisticated algorithms to identify the sound emitted by normal operations compared to that of the leak, thus identifying leaks immediately as they occur. Also, this technology is automatic thus eliminating human error. Noise loggers also have low maintenance and battery replacement cost for long-term use. This technology has a very high initial cost for a real-time monitoring system, and it does not identify the exact leak location without the use of correlators (Datamatic Inc. 2008).

A logger system is usually composed of a set of loggers that are placed throughout the network, a communication base that delivers collected data, and an analysis base that can be a desktop computer or a cloud engine using big data platforms. The main advantages of this system include the ability to preprogram the correlation and analysis which allows for faster analysis and detection and allows for conducting analysis at 


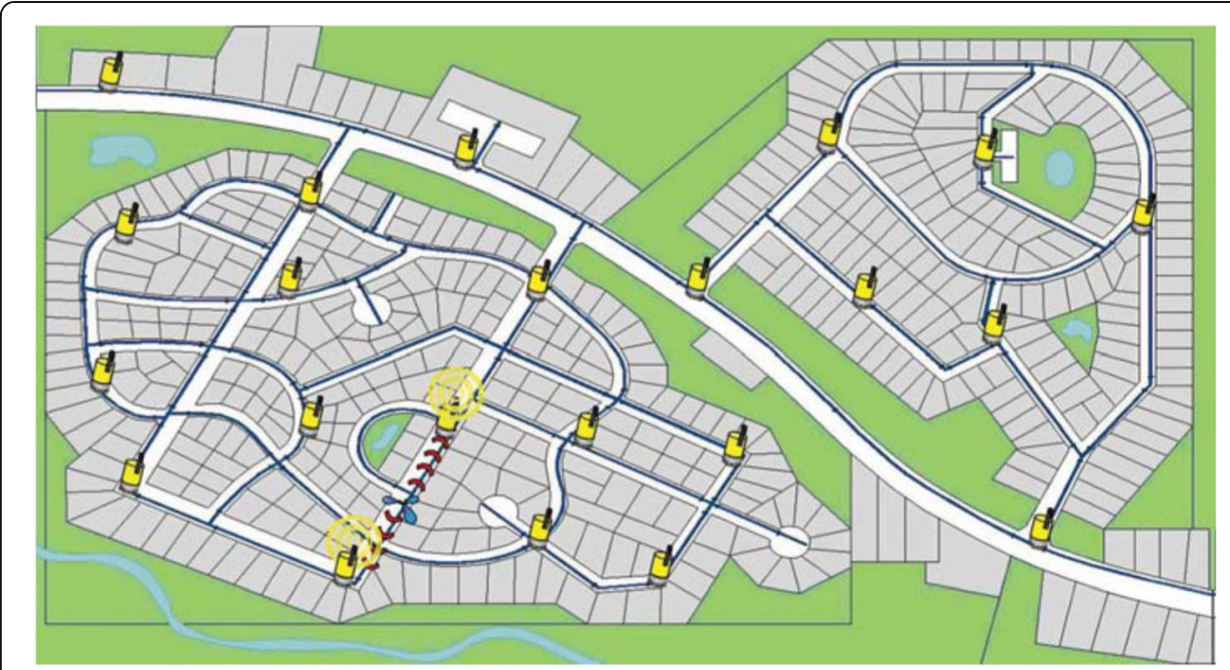

Fig. 11 Infrared image of a floor showing the distinctive color of entrapped moisture. The image displays an infrared of a floor with an adjacent legend that displays the variation in temperature

night which reduces the noise that may affect the loggers and can be done without the need for humans. Additionally, this system is utilized in highly pressurized water networks which allow the extended propagation of leak signal. Furthermore, multiple loggers may operate at the same time to provide multiple detections for more accurate results.

On the other hand, such systems have a room for improvement in correlationaccuracy by means of self-learning algorithms or collective thinking algorithms which allow the computational end of the system to keep improving constantly with new data. Additionally, logger systems require more efficient filtering algorithms that can eliminate "non-leak" noises that are often confused for leaks by such systems (El-Zahab et al. 2017; Hamilton and Charalambous 2013).

\section{Infrared thermography}

According to Fahmy and Moselhi (2009) "Thermography (IR) camera measures and images the emitted infrared radiation from an object. It can detect thermal contrasts on pavement surface due to water leaks." This technology has been tested on non-metallic pipelines and has shown accurate results, yet these results were not as accurate as the results provided by acoustic technologies such as geophones and are unreliable under the cases of damaged pipelines. Furthermore, IR Camera requires marking of the pipeline on the ground surface so that the machine can move above the pipeline. Also, the machine is profoundly affected by the surrounding weather and any variations in soil conditions and temperature. The infrared technology relies on the energy released by the vibration and motion of particles that release energy emissions based on their temperature. Infrared energy is not visible to the naked eye. Infrared thermography utilizes wavelengths that are limited to the electromagnetic range between 0.4 and $0.7 \mu \mathrm{m}$. Infrared technologies detect wavelength ranges larger than $0.7 \mu \mathrm{m}$, thus detecting the temperature 
distribution inside the pipe and in the surrounding environment to identify any temperature anomalies that might indicate the existence of a leak as shown in Fig. 12 (Varone and Varsalona 2012).

IR thermography is a powerful tool when utilized under the appropriate operating conditions, but it can merely provide a heat map of the surveyed area. The map cannot identify the causes of discoloration. The technology then requires advanced algorithms and mathematical approaches, specifically in image processing to allow for more accurate leak oriented analysis (Hamilton and Charalambous 2013).

\section{Tracer gas}

Tracer gasses is a leak detection technique that utilizes pressurizing nontoxic and insoluble gasses into leaks, these gasses contain ammonia, halogens, and helium, where helium is the most sensitive. Given that the utilized gasses are lighter than air they will tend to go out through leaks and then seep out through the soil or pavements. Later on, these gasses are traced and detected using a man operated detector to identify the locations of leaks through detecting the seepage of tracer gasses (KVS 2015).

The gas injection approach is reliable in all types of materials as it is not material type dependent. Additionally, tracer gases can detect leaks in pipelines that range from $75 \mathrm{~mm}$ to $1000 \mathrm{~mm}$ in diameter. Tracer gases are not conventionally used in larger pipelines due to the great expense associated with pumping a substantial amount of gas into the system. The method relies on knowing the flow of the water and blocking the gas from finding easier routes to exit the system. Blocking other routes is done by closing branches and cutting off the suspected leak area; this may cause interruption to the water distribution service. Furthermore, the gas may exit the ground from a different location than that of the leak; this is common in buried pipelines (Hamilton and Charalambous 2013; KVS 2015).

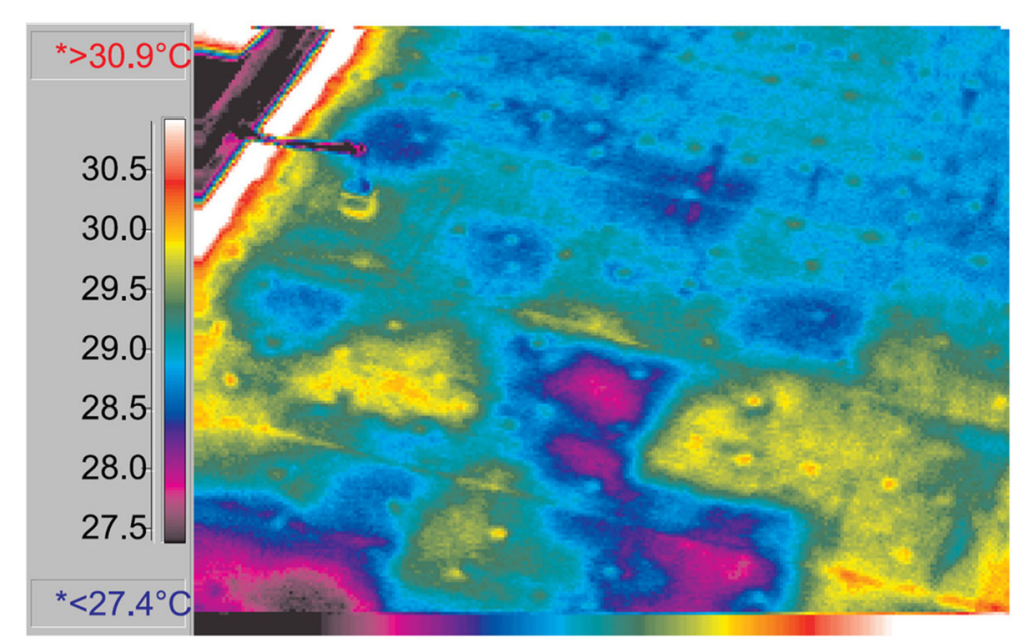

Fig. 12 Infrared image of a floor showing the distinctive color of entrapped moisture. (Kaplan 2007). The figure shows multiple loggers that are colored in yellow while being placed within the service openings in a pressurized water network 


\section{Ground penetrating radar}

The Ground Penetrating Radar (GPR) technology utilizes electromagnetic waves (between $125 \mathrm{Mhz}$ and $370 \mathrm{MHz}$ ) and transmits them into the ground to identify leak location via imaging the sub-terrain including the pipe and the leak. The advantages of this technology lie in its capability to detect leaks regardless of the material of the pipe, for any diameter size above one inch and reaching to a depth of $5 \mathrm{~m}$. Furthermore, this device can be easily transported between sites, and it does not require a lot of experience or training on behalf of the operator to operate it (Eyuboglu et al. 2003; Hamilton and Charalambous 2013).

On the other hand, this technology has multiple disadvantages namely requiring access to the road above the pipeline - thus disturbing traffic -, experience and training are required to accurately indicate the position of the leak and the dependency on the pipeline's bedding and surrounding conditions. Also, this technology is expensive where the machine price can range between 15,000\$ to 31,000\$ (United States Environmental Protection Agency 2009). Eyuboglu et al. (2003) developed a mathematical model that utilizes the amplitude of radar reflection to visualize the state of the pipe and detect precisely where the leak occurred. Figure 13 illustrates how the GPR is moved above the soil to detect the condition of the pipeline and the reflected imagery as a result of the movement. GPR systems require further support by means of decision support systems and competent algorithms that allow for faster and more accurate detection of leaks (Eyuboglu et al. 2003; Hamilton and Charalambous 2013).

\section{Leak detecting robots}

Multiple robotic devices were developed to perform in pipe inspection and determine leak locations in sewers. These devices can be wireless devices or cord connected.

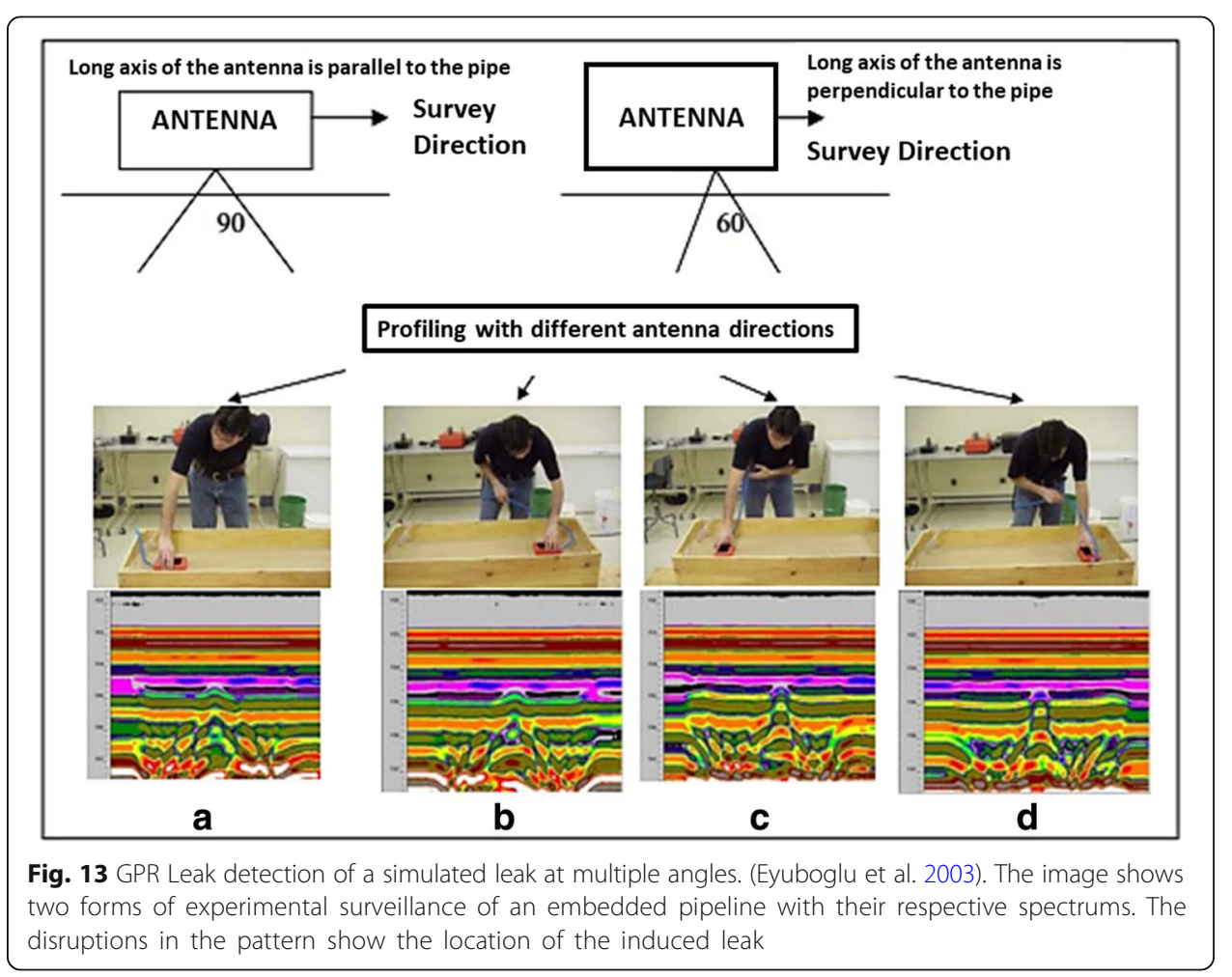


Furthermore, some leak detection robots can also perform leak repair tasks. One example to present in leak detection robots is "smart ball".

\section{Smart-ball}

Smart-Ball is a free-swimming technology developed to detect leaks from within live large water pipelines. Smart-ball technology is composed of a foam ball with an aluminum alloy core, within the aluminum core, a highly sensitive detection instrument is placed. Smart-ball does not create any noise when passing through the pipeline. Therefore, it can detect tiny leaks. Also, the Smart-ball has a location accuracy within $3 \mathrm{~m}$ of estimated leak location, it is very flexible due to its small size and can enter multiple sizes of pipelines. The Smart-ball requires two points of access to assess a pipe, a point for insertion and a point for extraction, and it is a non-destructive technology for leak detection. On the other hand, Smart-ball can only be operated by the manufacturing company only, and the ball might divert from the path it was required to search, or even the ball might get stuck (Puretech Ltd. 2015). PureTech Limited utilizes the acoustic sensor within the smart-ball device to listen to all the sounds emitted inside the pipe. Furthermore, PureTech utilizes its software to analyze the sounds they are hearing and identify the locations of leaks, valves, as well as air pockets. Figure 14. Further illustrates a smart ball passing through a pipeline and its possible outputs. The "SmartBall" system provided results within $3 \mathrm{~m}$ or closer in an experiment in Ankara in November 2011 were it detected 10 leaks during a 15-km inspection (Hamilton and Charalambous 2013).

\section{Wireless micro-electro-mechanical systems (MEMS)}

Micro-Electro-Mechanical Systems are microfabricated mechanical and electromechanical devices and structures. MEMS are usually composed of four main elements:

- Micro-Sensors

- Micro-Actuators

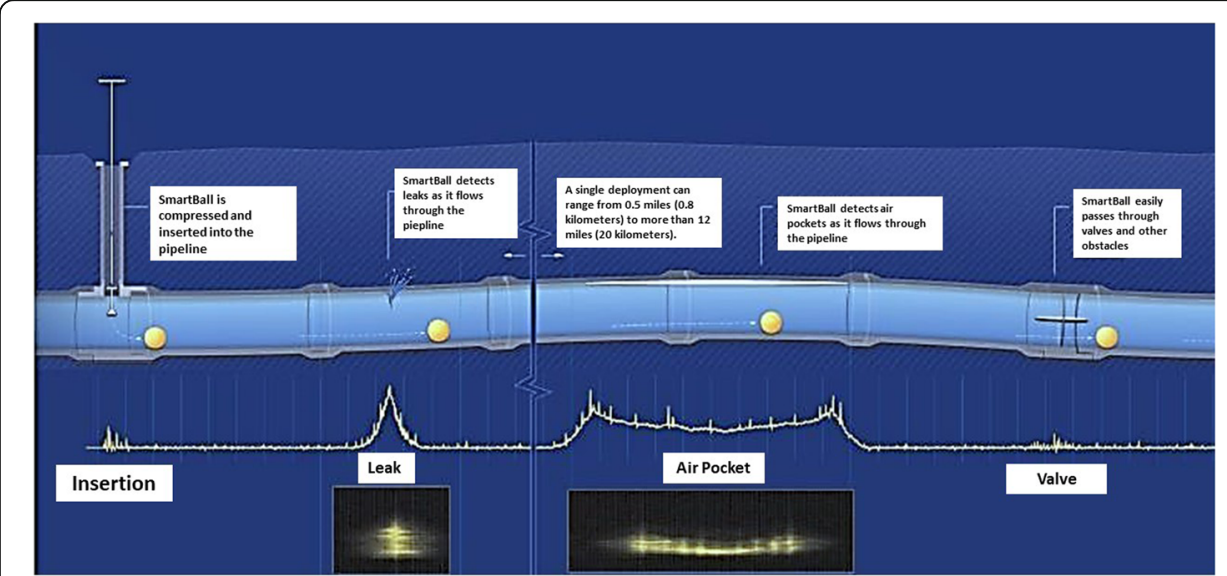

Fig. 14 Movement of Smart-Ball within a pipeline with results. (Puretech Ltd. 2015). The figure highlights the motion of a smart ball within a given tube and beneath it, the respective sound profile for each possible phenomenon within a pipeline 
- Micro-Electronics

- Micro-Structures (MEMS and Nanotechnology Exchange 2015).

Multiple types of MEMS were used in leak detection of water mains mainly accelerometers, acoustic, and thermal. MEMS technology provides continuous water network monitoring for any leaks from the moment they are placed. MEMS have proven to be cost-effective tools when it comes to the detection of leaks with their low cost and high sensitivity to signal anomalies. On the other hand, MEMS are viable when used in metallic pipelines, whereas other material types require further research due to the material-induced attenuation of high-frequency signals. Additionally, the application of MEMS is still mostly theoretical and requires further research. Furthermore, MEMS needs further testing on long pipes. As in loggers, the field of MEMS requires software and signal analysis improvements to become more viable as a realistic solution for leak detection (Hamilton and Charalambous 2013; Kim et al. 2011).

\section{Data analysis based methods}

In recent years, novel approaches have been developed that can be integrated with existing technologies to improve leak detection accuracy on all levels. Those approaches rely on have data analysis and range from statistical approaches to artificialintelligence based approaches.

One of the most common methods is regression analysis. Regression analysis relies on having a sizable collection of data points that represent multiple aspects of a selected study. For example, in the case of leak detection using noise loggers, the factors can include the highest and lowest amplitude of the signal, the incremental distance between two sensors, and the frequency of the collected signals. Regression analysis then tries to determine an equation that best fits the collected set of data points. After model development, the model is checked for statistical soundness using a series of statistical tests. Regression analysis is having a lot of success as an emerging approach in leak detection with pinpointing accuracies reaching $93 \%$. On the other hand, a developed model by regression analysis is situational, i.e. it can not be used for different pipelines or networks as they may have different operating conditions than the conditions where the model was developed. Regression models can be improved by integrating them with artificial intelligence, such that the model can be constantly improved with new data. Additionally, current regression models may acquire further accuracy by considering new characteristics of water networks such as pipeline material, soil type, pipeline age, and water pressure (El-Abbasy et al. 2016; El-Zahab et al. 2016).

Another popular method is artificial neural networks (ANN). ANN helps compensate for the incompleteness or randomness of collected data. The approach mimics the human cerebral network of neurons in operation. Their uses vary from leak detection in water networks to condition assessment. ANN is a directed learning approach, in other words, it relies on previously collected high-quality data to develop a baseline. The data is placed in an input layer and then analyzed in at least one hidden layer. Finally, the desired outputs are placed in a single output layer. ANN does not provide an equation as in regression analysis as its approach relies on black-box-like algorithms, yet it may 
provide better results in the field of leak detection than that of regression analysis (AlBarqawi and Zayed 2008; El-Abbasy et al. 2016).

Multiple other techniques are being utilized as well for leak identification and detection. Such techniques include Naïve Bayes algorithm (NB), Decision Trees (DTs), and Support Vector Machines (SVMs). The aforementioned techniques have presented great success in distinguishing leaks from other noises within the water network. Additionally, when the aforementioned techniques are coupled with a collective thinking code, their accuracy may reach $100 \%$ (El-Zahab et al. 2017).

\section{Conclusions}

Leak detection in pipelines is a growing research field and a growing industry that is driven by the criticalness of saving precious resources and preventing the fallout resulting from leaks. The early detection of leaks can prevent major gas spills, water seeping into the soil under highways resulting in sinkholes, minimizing infrastructure damage, preventing damages to the surrounding environment or personnel, and save money. Leak detection used to be divided into three phases according to the LLP system, but this system is deemed ambiguous, and therefore a new system is proposed, the ILP system. The ILP approach defines the boundaries between research fields. Identification comes first which is the phase that defines if the leak exists or not and differentiates leak data from other sources of data. Followed by localization, which narrows down the location of the leak to a specific element or segment. The final phase is pinpointing which specifies the exact leak location with high precision. Furthermore, two broad classes of leak detection systems are highlighted, and they are static leak detection systems and dynamic leak detection systems. Static leak detection systems provide early leak detection with minimal human interference. They can also localize and pinpoint. On the other hand, dynamic leak detection systems are used to verify the existence of leaks by mobilizing devices and personnel to suspected areas. This approach provides immediate localization and pinpointing for leaks, but allows leaks to grow if the response is not immediate. The best practice currently is a combination of both systems where the static system provides early detection and the dynamic system provides localization and pinpointing. The research in the static systems field promises that in the future, static leak detection systems will be highly capable of conducting the full ILP within seconds. The field of leak detection in pipelines is growing regarding technological uses as multiple new technologies are being utilized continuously to explore faster and more capable aspects. The field is expected to grow more as the need is increasing in the gas and water network sectors.

Abbreviations

3G: Third generation of mobile communication technology; ANN: Artificial Neural Networks; AWWA: American water works association; DT: Decision Tree; GPR: Ground penetrating radar; GSM: Global system for mobile communication; ILLP: Identify - Localize - Locate - Pinpoint; ILP: Identify - Localize - Pinpoint; IR: Infrared; LLP: Localize - Locate Pinpoint; NB: Naïve Bayes; SVM: Support Vector Machine; WoK: Web of knowledge

Acknowledgements

The authors would like to extend thanks to Dr. Eslam Mohammad Abdelkader and Mr. Nabil Younes for their input and support. 


\section{Funding}

There was no funding or grant to declare for this article.

\section{Availability of data and materials}

The data used in this research can be found available for free on the aforementioned databases, mainly Web of Knowledge. If a more specific set or feature of the data is required please contact the corresponding author.

\section{Competing interests}

The authors declare that they have no competing interests.

\section{Author details}

'Department of Civil and Environmental Engineering, Faculty of Engineering, Phoenicia University, Daoudiyeh, Lebanon. ${ }^{2}$ Department of Building and Real Estate (BRE), Faculty of Construction and Environment (FCE), The Hong Kong Polytechnic University, ZN716 Block Z Phase 8 Hung Hom, Kowloon, Hong Kong.

Received: 13 January 2019 Accepted: 21 May 2019

Published online: 11 June 2019

\section{References}

Aamo OM (2016) Leak detection, size estimation and localization in pipe flows. IEEE Trans Autom Control 61 (1):246-251 IEEE

Al Hawari A, Khader M, Zayed T, Moselhi O (2015) Non-destructive visual-statistical approach to detect leaks in water mains. World Acad Sci, Eng Technol, Int J Environ, Chem, Ecol, Geol Geophys Eng 9(3):230-234

Al Hawari A, Khader M, Zayed T, Moselhi O (2016) Detection of leaks in water mains using ground penetrating radar. World Acad Sci, Eng Technol, Int J Environ, Che, Ecol, Geol Geophys Eng 10(4):422-425

Al-Barqawi H, Zayed T (2008) Infrastructure management: integrated AHP/ANN model to evaluate municipal water mains performance. J Infrastruct Syst 14(4):305-318 American Society of Civil Engineers

Alkasseh JMA, Adlan MN, Abustan I, Aziz HA, Hanif ABM (2013) Applying minimum night flow to estimate water loss using statistical modeling: A case study in Kinta Valley, Malaysia. Water Resour Manag 27(5):1439-1455 Springer

Atef A, Zayed T, Hawari A, Khader M, Moselhi O (2016) Multi-tier method using infrared photography and GPR to detect and locate water leaks. Autom Constr 61:162-170 Elsevier

Beck SB, Curren MD, Sims ND, Stanway R (2005) Pipeline network features and leak detection by cross-correlation analysis of reflected waves. J Hydraul Eng 131(8):715-723 American Society of Civil Engineers

Begovich O, Navarro A, Sanchez EN, Besancon G (2007) Comparison of two detection algorithms for pipeline leaks. In: Control applications, 2007. CCA 2007. IEEE international conference on, pp 777-782

Belouchrani A, Amin MG, Thirion-Moreau N, Zhang YD (2013) Source separation and localization using time-frequency distributions: an overview. IEEE Signal Process Mag 30(6):97-107 IEEE

Billmann L, Isermann R (1987) Leak detection methods for pipelines. Automatica 23(3):381-385 Elsevier

Brennan MJJ, Gao Y, Joseph PFF (2007) On the relationship between time and frequency domain methods in time delay estimation for leak detection in water disribution pipes. J Sound Vib 304(1):213-223 Elsevier

Cataldo A, Persico R, Leucci G, De Benedetto E, Cannazza G, Matera L, De Giorgi L (2014) Time domain reflectometry, ground penetrating radar and electrical resistivity tomography: a comparative analysis of alternative approaches for leak detection in underground pipes. NDT \& E Int 62:14-28 Elsevier

Chraim F, Erol YB, Pister K (2016) Wireless gas leak detection and localization. IEEE Trans Ind Inf 12(2):768-779 IEEE

Colombo AF, Lee P, Karney BW (2009) A selective literature review of transient-based leak detection methods. J HydroEnviron Res 2(4):212-227 Elsevier

Covas D, Ramos H, De Almeida AB (2005) Standing wave difference method for leak detection in pipeline systems. J Hydraul Eng 131(12):1106-1116 American Society of Civil Engineers

Datamatic Inc (2008) Permalog + Leak Noise Loggers, used in conjunction with a MOSAIC Mesh Network or ROADRUNNER Mobile \& Handheld data collection platforms, are today's most powerful tool to protect precious resources and guard against costly and damaging water leaks. Datamatic Inc, Plano <https://www.environmental-expert.com/products/ permalog-leak-noise-loggers-122138> (Mar. 3, 2015)

Datta S, Sarkar S (2016) A review on different pipeline fault detection methods. J Loss Prev Process Ind 41:97-106 Elsevier

El-Abbasy MS, Mosleh F, Senouci A, Zayed T, Al-Derham H (2016) Locating leaks in water mains using noise loggers. Journal of Infrastructure Systems. 22(3):04016012

El-Abbasy MS, Senouci A, Zayed T, Mirahadi F, Parvizsedghy L (2014) Condition Prediction Models for Oil and Gas Pipelines Using Regression Analysis. Journal of Construction Engineering and Management. 140(6):04014013

El-Zahab S, Asaad A, Abdelkader EM, Zayed T (2017) Collective thinking approach for improving leak detection systems. Smart Water 2(1):3

El-Zahab S, Mosleh F, Zayed T, El Zahab S, Mosleh F, Zayed T (2016) An accelerometer-based real-time monitoring and leak detection system for pressurized water pipelines. Pipelines 2016:257-268

Eyuboglu S, Mahdi H, Al-Shukri H, Rock L (2003) Detection of water leaks using ground penetrating radar. In: 3rd International Conference on Applied Geophysics?Geophysics 2003

Fahmy M, Moselhi O (2009) Automated detection and location of leaks in water mains using infrared photography. J Perform Constr Facil 24(3):242-248 American Society of Civil Engineers

Fantozzi M, Calza F, Lambert A (2009) Experience and Results Achieved in Introducing District Metered Areas (DMA) and Pressure Management Areas (PMA) at Enia Utility (Italy). In: Proceedings of the 5th IWA Water Loss Reduction Specialist Conference, pp 153-160

Fuchs HV, Riehle R (1991) Ten years of experience with leak detection by acoustic signal analysis. Appl Acoust 33(1):1-19 Elsevier

Geiger G, Vogt D, Tetzner R (2006) State-of-the-Art in Leak Detection and Localisation 1 Regulatory Framework. Oil Gas Eur Mag 32(4):193 URBAN VERLAG 
Gertler J, Romera J, Puig V, Quevedo J (2010) Leak detection and isolation in water distribution networks using principal component analysis and structured residuals. In: Control and Fault-Tolerant Systems (SysTol), 2010 Conference on, pp 191-196

Gong W, Suresh MA, Smith L, Ostfeld A, Stoleru R, Rasekh A, Banks MK (2016) Mobile sensor networks for optimal leak and backflow detection and localization in municipal water networks. Environ Model Softw 80:306-321 Elsevier

Hamilton S (2009) ALC in Low Pressure Areas - It can be Done. In: Proceedings of Water Loss 2009 South Africa, CapeTown. IWWA, Mumbai, pp 131-137

Hamilton S, Charalambous B (2013) Leak detection. IWA Publishing, London

Hargesheimer EE et al (1985) Identifying water main leaks with trihalomethane tracers. J-Am Water Works Ass 77(11):71-75 American Water Works Association

Hauge E, Aamo OM, Godhavn J-M (2007) Model based pipeline monitoring with leak detection. IFAC Proceedings Volumes. 40(12):318-23.

Hogg RV, Tanis EA (2006) Probability and statistical inference. Prentice Hall, New Jersey

Huang S-C, Lin W-W, Tsai M-T, Chen M-H (2007) Fiber optic in-line distributed sensor for detection and localization of the pipeline leaks. Sensors Actuators A: Phys 135(2):570-579 Elsevier

Hunaidi $O$ (2000) Detecting leaks in water-distribution pipes. Construction Technol Update 40:1-6

Hunaidi O, Chu W, Wang A, Guan W (2000) Detecting leaks in plastic pipes. Am Water Works Ass J 92(2):82 American Water Works Association

Hunaidi O, Chu WT (1999) Acoustical characteristics of leak signals in plastic water distribution pipes. Appl Acoust 58(3):235254 Elsevier

Hunaidi O, Giamou P (1998) Ground-penetrating radar for detection of leaks in buried plastic water distribution pipes. In: International Conference on Ground Penetrating Radar

Hunaidi O, Wang A (2006) A new system for locating leaks in urban water distribution pipes. Manag Environ Qual: Int J 17(4): 450-466 Emerald Group Publishing Limited

Hunaidi O, Wang A, Bracken M, Gambino T, Fricke C (2004) Acoustic methods for locating leaks in municipal water pipe networks. In: International conference on water demand management, pp 1-14

Inaudi D, Glisic B, Figini A, Walder R, Belli R, Walder R (2008) Pipeline Leakage Detection and Localization Using Distributed Fibre Optic Sensing. In: 2008 7th International Pipeline Conference, pp 1-8

Kaplan H (2007) Practical applications of infrared thermal sensing and imaging equipment. SPIE press, Bellingham

Khulief YA, Khalifa A, Mansour RB, Habib MA (2011) Acoustic detection of leaks in water pipelines using measurements inside pipe. J Pipeline Syst Eng Pract 3(2):47-54 American Society of Civil Engineers

Khulief YA, Khalifa A, Mansour RB, Habib MA (2012) Acoustic detection of leaks in water pipelines using measurements inside pipe. J Pipeline Syst Eng Pract 3(2):47-54

Kim D, Ha J, You K (2011) Adaptive extended Kalman filter based geolocation using TDOA/FDOA. Int J Control Autom 4(2): 49-58

Krchnak K (2016) Water at the Forefront of the World Summit on Sustainable Development https://www.prb.org/ waterattheforefrontoftheworldsummitonsustainabledevelopment/ (Dec. 18, 2016)

KVS (2015) Tracer Gas Detection. In: Tracer Gas Detection <http://www.leakdetection-technology.com/science/leak-detectionwith-tracer-gas-methods.html (Mar. 9, 2016)

Lai WWL, Chang RKW, Sham JFC, Pang K (2016) Perturbation mapping of water leak in buried water pipes via laboratory validation experiments with high-frequency ground penetrating radar (GPR). Tunn Undergr Space Technol 52:157-167 Elsevier

Lay-Ekuakille A, Vendramin G, Trotta A (2009) Spectral analysis of leak detection in a zigzag pipeline: A filter diagonalization method-based algorithm application. Measurement 42(3):358-367 Elsevier

Lay-Ekuakille A, Vergallo P, Trotta A (2010) Impedance method for leak detection in zigzag pipelines. Meas Sci Rev 10(6):209-213

Lee PJ, Vítkovský JP, Lambert MF, Simpson AR, Liggett JA (2005) Frequency domain analysis for detecting pipeline leaks. J Hydraul Eng 131(7):596-604 American Society of Civil Engineers

Li W, Ling W, Liu S, Zhao J, Liu R, Chen Q, Qiang Z, Qu J (2011) Development of systems for detection, early warning, and control of pipeline leakage in drinking water distribution: A case study. J Environl Sci 23(11):1816-1822 The Research Centre for Eco-Environmental Sciences, Chinese Academy of Sciences

Martini A, Troncossi M, Rivola A (2015) Automatic leak detection in buried plastic pipes of water supply networks by means of vibration measurements. Shock Vib 2015:1-13

Mashford J, De Silva D, Marney D, Burn S (2009) An approach to leak detection in pipe networks using analysis of monitored pressure values by support vector machine. In: Third international conference on network and system security, 2009. NSS'09, pp 534-539

MEMS and Nanotechnology Exchange. (2015). "What is MEMS Technology?" <https://www.mems-exchange.org/MEMS/whatis.html> (Feb. 26, 2016)

Meniconi S, Brunone B, Ferrante M (2010) In-line pipe device checking by short-period analysis of transient tests. J Hydraul Eng 137(7):713-722 American Society of Civil Engineers

Mostafapour A, Davoudi S (2013) Analysis of leakage in high pressure pipe using acoustic emission method. Appl Acoust 74(3):335-342 Elsevier Ltd

Mpesha W, Gassman SL, Chaudhry MH (2001) Leak detection in pipes by frequency response method. J Hydraul Eng 127(2): 134-147 American Society of Civil Engineers

Pal M, Dixon N, Flint J (2010) Detecting \& locating leaks in water distribution polyethylene pipes. In: Proceedings of the world congress on engineering

Puretech Ltd. (2015). "Smartball." <https://puretechltd.com/technology/smartball-leak-detection/smartball/smartball_leak_ detection.shtml> (Feb. 26, 2016)

Rajani B, Kleiner Y (2001) Comprehensive review of structural deterioration of water mains: physically based models. Urban Water 3(3):151-164

Romano M, Woodward K, Kapelan Z (2017) Statistical process control based system for approximate location of pipe bursts and leaks in water distribution systems. Procedia Eng 186:236-243 Elsevier 
Royal ACD, Atkins PR, Brennan MJ, Chapman DN, Chen H, Cohn AG, Foo KY, Goddard KF, Hayes R, Hao T, Lewin PL, Metje N, Muggleton JM, Naji A, Orlando G, Pennock SR, Redfern MA, Saul AJ, Swingler SG, Wang P, Rogers CDF (2011) Site assessment of multiple-sensor approaches for buried utility detection. Int J Geophys 2011:1-19 Hindawi Publishing Corporation

Sadeghioon AM, Metje N, Chapman DN, Anthony CJ (2014) SmartPipes: smart wireless sensor networks for leak detection in water pipelines. J Sensor Actuator Netw 3(1):64-78 Multidisciplinary Digital Publishing Institute

Shibley JA (2013) Enhanced sonar Array target localization using time-frequency interference phenomena

Srirangarajan S, Allen M, Preis A, labal M, Lim HB, Whittle AJ (2013) Wavelet-based burst event detection and localization in water distribution systems. J Signal Process Syst 72(1):1-16

Stoianov I, Nachman L, Madden S, Tokmouline T, Csail M (2007a) PIPENET: A Wireless Sensor Network for Pipeline Monitoring. In: Information Processing in Sensor Networks, 2007. IPSN 2007. 6th International Symposium on, pp 264-273

Stoianov I, Nachman L, Madden S, Tokmouline T, Csail M (2007b) PIPENET: A wireless sensor network for pipeline monitoring. In: Information Processing in Sensor Networks, 2007. IPSN 2007. 6th International Symposium on, pp 264-273

Sun Z, Wang P, Vuran MC, Al-Rodhaan MA, Al-Dhelaan AM, Akyildiz IF (2011) MISE-PIPE: Magnetic induction-based wireless sensor networks for underground pipeline monitoring. Ad Hoc Netw 9(3):218-227 Elsevier B.V

United States Environmental Protection Agency (2009) Control and Mirigation of drinking water losses in distribution systems, Washington, DC

Van Eck NJ, Waltman L (2010) Software survey: VOSviewer, a computer program for bibliometric mapping. Scientometrics 84(2):523-538 Springer

Van Eck NJ, Waltman L (2014) CitNetExplorer: A new software tool for analyzing and visualizing citation networks. J Informetrics 8(4):802-823 Elsevier

Van Zyl JE, Clayton CRI (2007) The effect of pressure on leakage in water distribution systems. In: Proceedings of the Institution of Civil Engineers-Water Management, pp 109-114

Varone S, Varsalona P (2012) Detecting leaks with infrared thermography. Habitat MAgazine, New York, pp 48-50

Vítkovský JP, Simpson AR, Lambert MF (2000) Leak detection and calibration using transients and genetic algorithms. J Water Resour Plann Manag 126(4):262-265 American Society of Civil Engineers

Whittle AJ, Girod L, Preis A, Allen M, Lim HB, Iqbal M, Srirangarajan S, Fu C, Wong KJ, Goldsmith D (2010) WaterWiSe@SG: A testbed for continuous monitoring of the water distribution system in Singapore. Water Distrib Syst Anal 2010:1362-1378

Wu ZY, Sage P (2008) Water loss detection via genetic algorithm optimization-based model calibration. In: Water Distribution Systems Analysis Symposium 2006, pp 1-11

Wu ZY, Sage P, Turtle D (2009) Pressure-dependent leak detection model and its application to a district water system. J Water Resourc Plan Manag 136(1):116-128 American Society of Civil Engineers

Zhang J (1997) Designing a cost-effective and reliable pipeline leak-detection system. Pipes Pipelines Int 42(1):20-26

Zielke W (1968) Frequency-dependent friction in transient pipe flow. J Basic Eng 90(1):109-115 American Society of Mechanical Engineers

\section{Publisher's Note}

Springer Nature remains neutral with regard to jurisdictional claims in published maps and institutional affiliations.

\section{Submit your manuscript to a SpringerOpen ${ }^{\circ}$ journal and benefit from:}

- Convenient online submission

- Rigorous peer review

- Open access: articles freely available online

High visibility within the field

- Retaining the copyright to your article

Submit your next manuscript at $\boldsymbol{\nabla}$ springeropen.com 